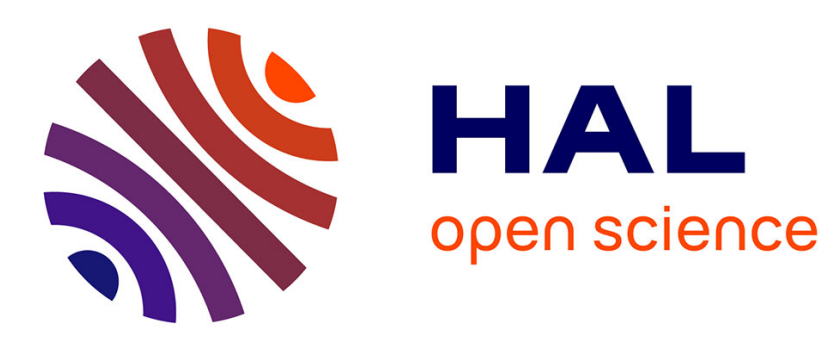

\title{
Analysis of conditions leading to a productive disciplinary engagement during a physics lesson in a disadvantaged area school
}

Patrice Venturini, Chantal Amade-Escot

\section{- To cite this version:}

Patrice Venturini, Chantal Amade-Escot. Analysis of conditions leading to a productive disciplinary engagement during a physics lesson in a disadvantaged area school. International Journal of Educational Research, 2014, 64, pp.Pages 170-183. 10.1016/j.ijer.2013.07.003 . hal-00976126

HAL Id: hal-00976126

https://hal-univ-tlse2.archives-ouvertes.fr/hal-00976126

Submitted on 9 Apr 2014

HAL is a multi-disciplinary open access archive for the deposit and dissemination of scientific research documents, whether they are published or not. The documents may come from teaching and research institutions in France or abroad, or from public or private research centers.
L'archive ouverte pluridisciplinaire HAL, est destinée au dépôt et à la diffusion de documents scientifiques de niveau recherche, publiés ou non, émanant des établissements d'enseignement et de recherche français ou étrangers, des laboratoires publics ou privés. 
Venturini, P., \& Amade-Escot, C. (2014). Analysis of conditions leading to a productive disciplinary engagement during a physics lesson in a deprived area school. International Journal of Educational Research, 64c, 169-182. DOI: 0.1016/j.ijer.2013.07.003

Accès à l'article publié : http://www.sciencedirect.com/science/article/pii/S0883035513000797

\section{Analysis of conditions leading to a productive disciplinary engagement during a}

physics lesson in a disadvantaged area school

Patrice VENTURINI \& Chantal AMADE-ESCOT

UMR EFTS, Université de Toulouse,

IUFM Midi-Pyrénées,

118 Route de Narbonne

31078 Toulouse cedex 04

France

patrice.venturini@univ-tlse2.fr ; amade.escot@univ-tlse2.fr

\section{Corresponding author}

Patrice VENTURINI ; Phone : 0033562252140 ; Fax : 0033562252172

\section{Abstract}

Our paper concerns the analysis of a teacher's practices leading to students' learning in an ordinary physics lesson. The study is conducted using the Joint Action Theory in Didactics (JATD) and the Productive Disciplinary Engagement (PDE) theoretical frameworks. Our qualitative case study is based on the video record of the lesson and on interviews with the teacher and students. In particular, we noted how the teacher managed the didactic 
07/04/2014 21:04

interactions, the characteristics of which may be partially related to problematizing, authority, accountability, and resources availability, four principles which foster PDE in more open contexts. 
The first aim of this article is to analyse how a physics teacher creates the conditions in which students are productively engaged in disciplinary learning during a lesson developed according to the French Scientific National Curriculum (FSNC) in a school located in a disadvantaged area. By “disadvantaged", we mean that this area is characterised by particular economical, demographical, social and cultural conditions: high unemployment, bad housing conditions, low level of people training, weak collective equipment and services, low number of French native speaking, illicit trafficking of all kinds.

For this purpose, we use the Joint Action Theory in Didactics (JATD) (Sensevy, 2007, 2011, and 2012) and the criteria characterizing Productive Disciplinary Engagement (PDE) provided by Engle \& Conant (2002) and Engle (2011). Their framework, developed beyond the scope of a community of learners, also points to four principles the teacher must respect to obtain PDE when he/she designs lessons. Therefore, the second aim of our article is to discuss the relations between our findings and the four principles proposed by Engle and Conant.

After describing the context and rationale of our research, we will develop the JATD framework. Because the PDE framework is presented by Forman and al. in the introduction of this special issue, we will only give its main outlines. These two frameworks will allow us to define our research questions and to design the corresponding methodology. This leads us to characterize the students' engagement and the teacher's practices, which are presented in the following part, then discussed and compared to Engle's principles before conclusions are drawn. 


\section{Context and rationale of the research}

In this section, we present some characteristics of the current, recently published FSNC and point out the interest we find in observing disadvantaged area schools. At the same time, we gradually explain the rationale of our research, which is summed up at the end of the section.

\subsection{An inquiry-based curriculum aiming to change teachers' practices and increase students' engagement in the study of science}

To raise and maintain students' interest in science and to engage them in studying the scientific disciplines, some changes have been made to the FSNC of secondary schools. The new curriculum imposes the use of a new teaching process, the "investigation process" (MEN, 2007, p. 6), which may be considered a French version of "inquiry-based teaching". However, in the new $\mathrm{FSNC}^{1}$, the content and time allotted for teaching science is constrained in the same way as in the previous curriculum, which was usually implemented in a traditional and transmissive way.

Therefore, we think it is useful to examine how an experienced teacher actually deals with this new and more open investigation process and how he/she adapts it to the maintained constraints of ordinary ${ }^{2}$ lessons. The analysis of his/her "ordinary" practices will be more instructive when the teacher attains the main curriculum aim, succeeding in engaging students to learn physics, because this school discipline seems characterized the most at present by lack of students' interest and engagement (Osborne et al. 1998). 


\subsection{Teachers' practices and students' learning and engagement in disadvantaged area schools}

Based on our own experience (Amade-Escot \& Venturini, 2009) and on that of other researchers (for a review, Rochex \& Kherroubi, 2004) we assume that teaching and learning practices are more interesting and richer to observe in classes located in disadvantaged areas. Research in sociology showed how social inequalities and spatial disparities work together to lead in these areas to a high concentration of children with strong school difficulties and high levels of school failure. Thus, there, every teacher's unsteady action is immediately sanctioned by students' disengagement and is consequently easy to spot, whereas such an event may go practically unnoticed in an ordinary school because of students' habits and their good will. According to Rochex (1997), all that occurs in a class located in a disadvantaged urban area amplifies what might occur in an ordinary class, as through a magnifying glass. Rochex's viewpoint is all the more interesting because combining students' engagement in the given tasks with in-depth learning is often a challenge for teachers working in such areas. Research literature has actually shown that, in that kind of school, teachers have to deal with the difficulty of maintaining both conceptual learning and engagement in school tasks (Bautier \& Goigoux, 2004; Rochex \& Kherroubi, 2004). The latter is favoured by an immediate achievement in the task and this occurs more easily when the tasks are simple and closed, without need for in-depth disciplinary reasoning. In that case, if students are engaged, their engagement does not lead to real disciplinary learning because significant disciplinary contents or practices are not imbedded in the given tasks. 
Thus, analysing how teachers carry out their intention to foster students' engagement without sacrificing disciplinary learning and succeed in doing this in disadvantaged areas, where students' disengagement is common may have great potential.

To sum up the rationale of the research, our aim is to analyse the ordinary practices of a physics teacher working in a class located in a disadvantaged area, who intends to teach contents according to the "investigation process" alike as defined by the FSNC, and succeeds in productively engaging students in the disciplinary learning tasks.

\section{Theoretical frameworks}

The study was conducted using the JATD framework and the PDE criteria that allowed us to formalize our research questions.

The JATD (Sensevy, 2007; Sensevy, 2009; Sensevy, Schubauer-Leoni, Mercier, Ligozat, \& Perrot, 2005, 2011, 2012) was designed to describe phenomena linked to the transmission of knowledge. This theoretical framework gives an account of the teacher's and students' actions as well as the changing context in which these actions take place. Thus, it is an analytical framework that describes the conditions under which the knowledge is conveyed in the class, whatever the way it is conveyed. Formally, this framework does not encompass prescriptive aims. The JATD considers knowledge constructed in the classroom as the result of a joint production by teacher and students. It takes the teacher, the students and knowledge into account simultaneously, coordinating thus aspects that are usually separated. This ternary approach allows us to examine the conditions under which the teacher engages students to learn physics knowledge. Moreover, this theory has already been used to analyse the unfolding of physics lessons 
(e.g. Tiberghien, Malkoun, Buty, Souassy, N. \& Mortimer, 2007; Venturini \& AmadeEscot 2009b).

To identify whether the students are really engaged in learning physics, the criteria for characterizing productive disciplinary engagement, provided by Engle and Conant (2002) or by Engle (2011) appear to be relevant and easy to exploit in our research context comprising of a reduced number of students. The authors also provide us with four principles the teacher has to apply to foster PDE, which have already been applied in connection with analyses of physics lessons (Scott, Mortimer \& Aguiar, 2006).

\subsection{Elements of the joint action theory in didactics}

Borrowing concepts developed by French didactics, and shedding new light on them with pragmatist theories, the JATD attempts to account for both the socio-historical and situated dimensions of the didactic action ${ }^{3}$, trying to model the human transactions concerning the transmission of a socio-historically built culture (Ligozat \& Schubauer-Leoni, 2009).

The JATD models the didactic interactions between the teacher and the learner as an organically cooperative learning "game", i.e. "a joint game within a joint action" (Sensevy, 2009, p. 115). Of course, such a game involves separate and distinct acts corresponding to different personal aims but they are "bound together to make the collective action progress ... in some cooperative patterns" monitored by the teacher (Ligozat \& Schubauer-Leoni, 2009, p. 89). Collins \& Ferguson (1993), Morrison \& Collins (1996) already considered the flow of interactions between the teacher and the learner as a set of games, more precisely a set of "epistemic" games. Both learning games and epistemic games deal with the social construction of knowledge and allows considering definition/entry, rules, strategies etc. to think the processes at stake. But the former focuses on the ways the 
teacher and the student(s) act jointly within an environment they contribute to construct, while the latter is more centred on the knowledge itself and its structures ${ }^{4}$. In a more general way, considering social practices (here didactic practices) as a set of games (here learning games) also refers to the "social games" defined by Bourdieu (1992) and to the “language games" introduced by Wittgenstein (1953/1997).

To describe the learning game as it occurs in situ with regard to a particular piece of knowledge, the researcher uses a set of specific descriptors: the "didactic milieu" and "didactic contract"; the set of geneses (mesogenesis, chronogenesis, topogenesis); and the types of teacher's actions (defining, devolving, regulating, institutionalizing). We give a brief description of this system of concepts below.

\subsubsection{Didactic milieu and didactic contract}

According to Brousseau (1988/1997, p. 227-279), the milieu encompasses all that acts on the student and/or that the student acts on and in reference to the JATD, we include the teacher in this definition as well as the student. Therefore, the milieu involves conceptual and material components as well as social and semiotics aspects. Widely, it includes both local/situational and historical/cultural components. It evolves regularly as the lesson progresses (Amade-Escot \& Venturini, 2009). Thus, referring to the notion of "context" as defined by Mercer $^{5}$ (2000), we might consider the didactic milieu as the "context" of the didactic joint action.

The didactic contract is considered as "a set of largely implicit rules, of usual ways of acting (with regard to the subject being studied) that the teacher and the students find suitable in the context of the didactic relationship" (Sensevy et al., 2005, p. 158). The concept of « didactic contract» appears in didactic theories in the 80s (see Brousseau, 
1988/1997; Brousseau \& Warfield, 1999). One can see obvious connections between the concept of didactic contract and that of "normative identity" (Cobb, Gresalfi \& Hodge, 2009, p. 43).

A learning game is defined by a particular contract and a particular milieu. To characterize the joint didactic action, the researcher must identify how students orient their actions when playing the learning game, either by enacting the didactic contract habits or by building epistemic relations with the milieu.

\subsubsection{The threefold set of geneses}

Mesogenesis (i.e. genesis of the milieu) describes the process by which, over time, the teacher (re)organizes the milieu and the milieu is reorganized by the students' interventions. It is a threefold meaning-making process that the researcher can characterize by identifying "1) the set of objects that participants indicate to themselves, 2) the meaning that they may ascribe to their own actions with these objects, 3) the control they gain from it and that may be re-allocated in further experiences" (Ligozat \& Schubauer-Leoni, 2009, p. 90).

Chronogenesis (i.e. the genesis of the didactic time) describes "the evolution of the knowledge proposed by the teacher and studied by the students, as it unfolds during the joint action" (Sensevy, 2009, p. 117). In other words, the chronogenesis is related to the pace of academic work. Its evolution produces, for the students and the teacher alike, a temporality defined as the didactic time (Sensevy et al., 2005, p. 159).

Topogenesis (i.e. the genesis of positions) describes how the teacher manages his/her engagement in the joint action, and allocates a role to the students, collectively or 
individually. Thus, it concerns the division of the activity and leads to less or more shared responsibilities towards the knowledge progress.

Because the teacher is the leader of the asymmetric didactic relationship, the chronogenesis and the topogenesis are strongly related to his/her actions within the didactic contract. Thus, to every stage of the mesogenesis correspond a topogenetic state and a chronogenetic state which allow the dynamics of the teacher's and students' joint action to be described (Amade-Escot \& Venturini, 2009).

\subsubsection{The types of teacher's actions}

This set of categories is used to describe the way the teacher intervenes when the learning game is played, to start and maintain the didactic relationship (Sensevy, 2009, p. 116):

- Defining; the teacher defines the rules of the learning game and the objects which are included in the game, for the students to be able to play the game.

- Devolving; the teacher acts over the game in such a way that students accept to play proprio $\mathrm{motu}^{7}$ and to establish a relation as appropriate as possible to the milieu.

- Regulating; as the students do not immediately play with a pertinent strategy, the teacher must intervene to modify their behaviour in order for it to become more relevant to winning the learning game. By doing this, he/she reduces or increases the level of certainty/uncertainty of the students' actions.

- Institutionalizing; during the game, the teacher has to point out to the student that his/her activity has reached the knowledge at stake, which is valid not only in the classroom but also in a larger and external social community. 
This set of JATD elements allows the dynamics of the interactions to be grasped as evolving processes and the kind of cooperation about knowledge between the teacher and students to be identified. Let us now consider the PDE framework.

\subsection{Productive disciplinary engagement}

Forman and al. (this issue) define PDE and formulates four principles which determine this particular student behaviour. So, in this section, we only mention some elements of this framework to give the reader some landmarks.

Engle \& Conant (2002, p. 402) inferred greater engagement when, in particular, “(a) more students in the group sought to make, and made, substantive contributions to the topic under discussion; (b) students' contributions were more often made in coordination with each other, rather than independently of each other; (c) few students were involved in unrelated "off-task" activities". This engagement is "disciplinary" when "there is some contact between what students are doing and the issues and practices of a discipline discourse" (ibid., p 403). According to Ford and Forman (2006, p. 12-16) science disciplinary practices include social, material and rhetorical dimensions. Actually, science's rationality and development are based on debates occurring in scientific communities. These debates are ultimately arbitrated by material aspects which also characterize what the discussions are about and why; scientific communities can be considered as involving the two roles of "constructor" and "critiquer" of claims regarding matters of facts, methods and values, working in interplay, and needing the mastery of a particular way of interacting. Finally, the engagement is "productive" when students "make intellectual progress or, in more colloquial language, get somewhere" (Engle and Conant, 2002, p. 403). 
To foster PDE, four principles must be emphasized during the design of the lessons and their development (Engle, In Press):

- problematizing content: "individual or collective actions that encourage uncertainties related to the discipline to be taken up by students";

- providing relevant resources (like technological tools, artefacts, practices, materials, books, sufficient time as well as local and momentary elements due to short teacher's interventions in the class ${ }^{8}$ ) to balance the uncertainty associated with the problematizing;

- giving students intellectual authority so they become really engaged in solving a problem. Engle distinguishes four levels of authority: learners can be "authorized" to share what they really think, recognized as authors of their own ideas, recognised as contributors to the ideas of others, and considered as a "local authority" about a topic;

- holding students accountable to others (to “one's peers, to oneself at other times, to local and outside disciplinary authorities") and to the discipline (facts, procedures, practice, norms, theories) to balance authority.

According to Engle and Conant (2002, p. 401) these principles are "general enough to be useful for understanding other cases [than those of communities of learners in which they have been built] and guiding future design efforts".

\subsection{Research questions}

Drawing on these two theoretical frameworks, the rationale of our research leads us to the following questions.

- In this disadvantaged area, are students really productively and disciplinarily engaged? 
- How do mesogenesis, chronogenesis and topogenesis evolve in the course of the lesson? How does the teacher intervene when the learning game is being played? In particular, what are the spaces for and use of definition, devolution, regulation and institutionalization in the observed learning games?

- Whether PDE exists, how can these observed dynamics and intervention modalities be related to the four principles of PDE?

These two last questions are really the core of our research: analysing how this physics teacher succeeds in engendering students' PDE in this disadvantaged area and how the key-factors pointed out in the analysis are related to the four principles of PDE. Moreover, shedding light on these relations leads to connect some elements of the JATD and the PDE theoretical frameworks and discuss them.

\section{Methodology}

The mainly qualitative methodology calls for different types of data. Before listing them and describing their treatment, we describe the environment in which we gathered them.

\subsection{Class environment}

The study took place in a middle school located in a disadvantaged area of the toughest suburb of a French town. According to Marie (pseudonym), the physics teacher who accepted us in her class, student and teacher turnover is very high in this school. Physical and verbal aggression among students is recurrent, thefts are frequent, violence is usual. The class observed (year 8) was made up of 15 students, 10 girls and 5 boys. This low number of students is linked to the school membership in a "priority education zone". Schools belonging to these zones of disadvantaged areas receive from the governmental 
administration extra financial assistance (money and teaching positions) to support adequate educational opportunity for their students. Marie describes it as having "good dynamics.” Actually “although class control remains a continuous problem, the oral participation and the activity during lab work are very high" (Marie's interview). However, according to her, the students come up against serious difficulties, mainly with writing, all the more so because "they do not work at home"; ten of them show "very poor performance at school". As for Marie, she has spent ten years in service, teaching in various disadvantaged areas and is thus very experienced in this kind of school. In spite of these difficult working conditions, her aim remains to reach the revised FSNC standards (MEN, 2007).

\subsection{Data collection}

The methodology is based on the articulation and cross checking of information derived from video recordings of lessons (Derry, 2007) and different interviews with the teacher and students. Various data were collected:

- Teacher's and students' actions in the class: we videoed three consecutive lessons concerning the physics theme "light sources, vision of an object". This theme is the first of the syllabus dedicated to geometrical optics and deals with 1) primary and secondary sources, respectively characterized by the emission and the diffusion of light; 2) vision, possible only if the emitted or diffused light penetrates the eye (MEN, 2007 p. 120). The first of the three videoed lessons dealt with point 1 (primary and secondary light sources); it unfolded in two successive half classes and this paper primarily reports the analysis of the first one ( 5 boys and 3 girls) during which students seemed to be particularly engaged in schoolwork, which is why we chose to analyse it. 
The other lessons dealt with point 2 (see Venturini \& Amade-Escot, 2009b). We also gathered all the documents the teacher handed out for the students to fill in during the lessons.

- Teacher's didactic aims and a posteriori analyses for each period: using interviews before (ante) and after (post) each lesson, we collected information about the class and the school context, Marie's aims for the different lessons and her analysis of the lessons.

- Students' physics learning: We asked five students the teacher pointed out as representative in terms of physics school results to reformulate orally what they did and did not grasp from the lesson, during a collective interview after the lesson.

The lesson interactions and the interviews were transcribed.

\subsection{Data analysis}

Establishing relations between different parts of this corpus leads to the construction of didactic phenomena: from the didactic observation of the lesson and the analysis of interviews, facts are reconstructed, not in order to relate them but to try to explain and to understand the progress of the knowledge in the teaching-learning system. This process "has something in common with a kind of inquiry which proceeds by reciprocal questioning of the different pieces of the corpus and of the different traces it involves. This analysis is developed in an ascending way ... seeking by induction to go back to different facts susceptible to support the understanding of a particular trace" (Leutenegger, 2003, p. 561). Following this researcher, we considered the video of the observed lesson as the main corpus. As usual in didactics methodology, we first condensed these data, building 
the "synopsis of the lesson" (ibid.) which related the different tasks and their aims as well as the resources at students' disposal to carry them out (see Table 1 in the next section).

Then, we carried out a qualitative analysis of the video using the Transana software ${ }^{9}$. With the help of the transcript of the verbal interactions, we identified successive clips. Each clip represented an "episode" that was "a coherent set of actions and meanings produced by the participants in interaction, which have a clear beginning and end and can be easily discerned by the previous and subsequent episodes" (Mortimer et al., 2005, p. 6). The lesson we observed lasted 55 minutes and comprised 70 episodes, the average duration of which was 47.1 seconds.

Analysing the students' and teacher's conversations and behaviour during the class activities, we assigned keywords to each episode according to both theoretical frameworks. The analytic keywords related to the JATD involved specifying the set of geneses (topogenesis, chronogenesis, mesogenesis) and the four types of the teacher's actions (defining, devolving, regulating, institutionalizing). They also concerned the different criteria characterizing the existence or not of PDE, as defined previously. The choice of keywords was based both on research literature and on an inductive analysis of the transcript and the video. Working independently of each other, each researcher assigned keywords to each episode. The rate of agreement was $85 \%$. The cases of disagreement $(15 \%)$ were discussed until we reached common interpretations of the data.

With Transana, we checked the existence of productive disciplinary engagement, examined how the teacher dealt with class management, and explored qualitative and quantitative relationships between the applied keywords and the different episodes during the lesson. 
To reinforce trustworthiness of our inferences, we cross-checked the interpretation of the Transana outputs with the teacher's and the students' interviews in which we took the spoken passages that, in our opinion, gave sense to some events spotted in the video.

\section{Structure of the lesson and didactic analysis of knowledge at stake}

Before describing our findings, we think it would be useful to give the reader a global view of the lesson, its structure and its successive stages (Table 1).

\section{Insert here Table 1}

Fully in accordance with the FSNC for the content and for the investigation process, this lesson is the first step for progressively building a scientific model of vision. According to the two most frequent misconceptions at this age, light intervenes only to constitute a "sea of light" in which the object is bathed, or it only lights the object, and in both cases, this is the only reason why the object is seen (Andersson \& Karrqvist, 1983; Selley, 1996). In these two everyday spontaneous models, the light is not propagated up to the eye. The scientific model according which a part of the radiation diffused by a lighted object gets into the eye practically does not exist at this age. Moreover, the emission of light is a property clearly and only attributed to some objects (lamps, sun, etc.) and not to secondary sources. Thus, the didactic stakes in this lesson from minute 3 to 48 (i.e. a secondary source diffuses the light it receives) correspond to a significant obstacle during the construction of the scientific model of vision.

\section{Findings}

As specified when listing our research questions, our first aims were to describe the nature of the students' engagement by relating it (or not) to PDE. This is reported in the first 
section. The second section concerns the description based on the JATD of the teacher's practices we observed in the class.

\subsection{Forms of students' engagement in the lesson}

The analysis of the interactions revealed a productive disciplinary engagement, quite uncommon in such classes, in which it is very difficult to maintain a disciplinary activity, as pointed out in the literature (Bautier \& Goigoux, 2004; Rochex \& Kherroubi, 2004).

Regarding PDE criteria proposed by Engle \& Conant (2002, p. 402) and already stated in the previous pages, the following indicators provided by Transana software confirmed that students were engaged in learning. The discourse in the class focused on optics for 36 minutes out of $55^{10}$ (see Table 2 for a recap chart of the Transana outputs used in this paper). For each optics episode (49 out of 70 ), more than $80 \%$ of students were listening or working individually when asked and, when collective work was proposed (during 26 minutes), at least 40 to $60 \%$ collaborated with others regarding the knowledge at stake. Their discourse was coordinated with others for 13 minutes (out of 26), and 8 minutes of students' questions + or inputs were connected with the optics topic under discussion. To summarize, most of the students contributed to the progress of knowledge: they argued about the topic put under discussion by the teacher, and the discourse of one often interacted with those of the others. They collectively tried to interpret the experiments, to put new questions into words, and, after that, they individually tried to formalize the description and the interpretation of these experiments.

Besides being engaged, the students were "disciplinarily" engaged. In this lesson, $65 \%$ of the time (36 minutes out of 55) was dedicated to optics, and during those moments, there was some contact between what students were doing and scientific practices. Thus, they 
debated the scientific question (the classification of different light sources, cf. Table 1, minutes 6 to 12). During these exchanges, they worked in interplay which allowed them to emit predictions about the visibility of a ball lit in different ways (minute 13), they referred to an experiment to check (minute 15) and they debated to interpret their observations (minute 21). During the oral correction (minutes 38 to 45) concerning the classification of different light sources, they justified their proposals by drawing on material evidence. Thus students worked on scientific content and were also engaged in practicing parts of social, material and rhetorical aspects that characterize scientific work according to Ford and Forman (2006, p. 12-16). Even though the students were not fully able to put forward strongly constructed proposals ${ }^{11}$ and though they did not really play the role of "critiquer" (played by the teacher), they practiced elements of scientific practices (social work, predictions, justifications drawing on material evidence, debate... See the students' activities in Table 1). Taking into account the FSNC constraints, the fact that it was their first optics lesson and that they began physics only five months ago, we claim that in this lesson students practiced scientific work at a consistent level, at least as consistent as it could be in these conditions. We claim that this point of view fits Engle and Conant's one when they wrote: the students "made contact with disciplinary issues and practices [by being] attuned to an important value in scientific and scholarly work that claims need to be supported by evidence... [and having] the content of the debate focused on issues and used types of evidence recognizably related to biological discourse and classification” (2002, p. 420), and here to physics discourses and model of vision.

Lastly, there are clues attesting that this disciplinary engagement was also productive. Most of the students produced scientific reasoning during 4 minutes towards the end of the 
lesson and all students except 2 gave fully correct answers to the final exercise which invited them to classify 7 light sources. This was also confirmed by the students' collective interview which highlighted the fact that, afterwards, they could sum up the main points of the lesson related to the concepts of primary and secondary source at stake (Extract 1).

Ho: we learnt there are two kinds of lights, there are primary lights and secondary lights, the primary lights, they produce their own light themselves, and, the "secondary", someone sends a quantity of light, and after it throws it out, it gives out another part, so we can see it.

Ka: it diffuses, yes, it receives and it gives out.

\section{Extract 1. Students' verbal interactions (collective interview after the lesson).}

All these facts lead us to consider that, during this lesson in a disadvantaged area, the teacher succeeded in fostering students' PDE during the learning tasks, applying process and content as defined by the FSNC. Using the JATD framework, let us now examine how she dealt with the class to reach the FSNC aims,

\subsection{Description of the teacher's practices}

The analysis of the interactions reveals a specific teacher's behaviour when organizing the learning environment. Throughout the lesson, she maintains a subtle balance between the problems and questions she puts to the class and the elements used to answer them (elements provided by material experiments, by students or by her). This specific mesogenetic management is associated with a balanced topogenesis and a particular chronogenesis, described at the end of this section. 


\subsubsection{Problems and questions, as a way to devolve the learning game}

First, Marie encourages students to take on intellectual problems related to the topic under discussion. For example ${ }^{12}$ she starts the characterization of primary and secondary light sources by calling on students to explain the fact that a white ping-pong ball is also a light source, just as a lamp or the sun are (Extract 2).

T(Teacher): ... I tell you that the snow, the sun, a lamp and a ping-pong ball are light sources. Who wants to say something about this statement?

Extract 2. The teacher asks the students to discuss various light sources (Min 7: 30).

In addition, she aims to open the discussion and at times prioritizes a dialogical communication, submitting different points of view to debate (Mortimer \& Scott, 2003):

T: Housseme, why do you put together the sun and the lamp on the one hand, and why do you put the snow and the ball on the other hand? (Min 10:00)

T: Ramayssa would associate the sun and the snow, and the lamp and the ping-pong ball. Why Ramayssa? (Min 10: 26)

Extract 3. The teacher opens the debate about two viewpoints related to different light sources.

Just before ( $\min 9: 30$ ) when she asked the students to classify the four light sources (Table 1, min 6-12), Housseme rightly and immediately associates the lamp and the sun on the one hand, the snow and the ball on the other hand. Nevertheless, Marie appeals to Ramayssa who suggests grouping the sun and the snow on the one hand and the lamp and the ping-pong ball on the other, each student then having to argue about their choice. The teacher does not only ask for the students' points of view, she tries to contrast them 
(Extract 3). Moreover, before doing an experiment at minute 13 to answer the question "do we see a white ball in darkness?" (cf. Table 1), she asks the students to predict what will happen and their propositions also give rise to a discussion. In that debate as in the others, every student is accountable to others (students and teacher) for the arguments he or she uses during the discussion.

In our opinion, this teacher's behaviour can be taken as a problematization of the knowledge at stake that maintains the students engaged in solving the questions, and therefore plays a part in the devolution process of the learning game.

\subsubsection{Elements usable to deal with problems and questions as results of a maieutic ${ }^{13}$ process, specific regulations, and institutionalizations}

The analysis points out that the exchanges are based on a collective maieutic Platonic process including most of the students. Extract 4 shows how Marie systematically questions the students, aiming for them to express what they know to ensure the progress of the knowledge in the class. This process appears during 17 episodes (out of 49 devoted to optics).

T: The light goes away from the lamp; it goes into the whole room... Particularly, it goes onto...

Ra: Onto the ball.

Si: It hits the ball

T: It "hits", hum ... (The teacher does not agree with the verb Sihène has chosen and she implicitly asks for another expression)

Ho: The light, it sends things to the ball.

T: The lamp "sends" light to the ball. And then? 


\section{Ho: And then, we see it!}

\section{T: How does that happen?}

Ho: Because, because... The lamp sends light to the ball, that is that, and then, we can see it.

\section{T: How does that happen?}

Ra: thanks to the light too.

Ka: it lights up the ball because the light is received in the good side that is that!

Extract 4. Maieutic process used by the teacher to model the phenomenon of diffusion (Min. 22 to 23).

With the aim of facilitating the students' reasoning, the teacher clearly identifies the knowledge at stake in each step. She delimits the material and conceptual elements submitted to discussion, highlighting the relevant features of the didactic milieu. These kinds of regulation that help the students to improve their strategies in the learning games appear during 19 episodes (out of 49). For example, when the question is to model the phenomena of diffusion, and because the students almost unanimously contested that a secondary source has the property of giving out light, the teacher dogmatically maintains: "I personally say that the ball is a light source" (min. 8). This element is then no longer an object about which students can debate, but now a base on which they can develop reasoning in the didactic milieu. Thus it may be interpreted within the JATD as a knowledge institutionalization. Later (min. 13), the teacher presents an experiment during which she will light up a white ball with white and red lamps in the darkness. She asks the students to put forward hypotheses about what will happen watching the lamp and watching the ball (min. 13 to 15). This injunction highlights the relevant features the students will have to observe during the experiment (min. 16) and allows them to think 
they are linked. This way of working is systemically used because "we do not carry out an experiment to handle scientific equipment, there is an [conceptual] aim, and students must not get involved in headlong experimenting” (interview ante)

As just mentioned, the teacher frequently institutionalizes elements of knowledge as it progresses in the lesson (13 episodes out of 49). Thus, the students can regularly draw on these stabilized elements for their scientific reasoning. However, although students do participate in the progress of knowledge, they have difficulty in formulating the conclusions Marie hopes for at the end of this and other discussions. Thus, she is forced to conclude the interactions herself when they become fruitless and demotivating. This is the case in extract 5, during which students have trouble abandoning their spontaneous model of vision and contest the fact that a secondary source can be a light re-emitter.

T: So, I say the ball gives light into your eyes. That is what is written. Is it possible? Ho: Yes. // Ka: No. //Mo: No. // Ho: Yes!

Ka: It is not possible

Ho : I don't know.

Ka: Because the ball, it does not produce light.

T: Does it receive light?

Students (together): Yes, yes.

T: Can it throw it back?

Students (together): No!

T: No?

Ho: Yes. // Ka: Noooo, the lamp just lights up the ball, and the ball does not throw light back! 
T: And yet, that is what happens! [And then, the teacher gives the model]

Extract 5. Teacher's conclusion of a discussion (min. 25). This extract closes the exchanges a part of which is presented in extract 4.

To sum up, Marie delimits the didactic milieu, points out its relevant features for reasoning, highlights its significant points ${ }^{14}$, gives the correct responses when students fail to obtain them ${ }^{15}$. In accordance with the JATD, we interpret all these actions as mesogenetic regulations, that is to say as teachers' interventions on material and conceptual elements that modify the milieu and provide semiotic clues in order that the students play more adequately the learning game. In association with her recurrent institutionalizations of new knowledge, these regulations contribute to the students' scaffolding ${ }^{16}$ in the course of the transactions.

\subsubsection{Meso, topo and chronogenesis}

The two previous sections account for the mesogenesis. Due to the joint action of the teacher and the students, the milieu evolves during the period, sometimes more open (devolution, problematizing), sometimes more closed (students' answers, teacher's regulations and institutionalizations). This alternation provides knowledge progress during the lesson.

This type of mesogenesis implies that students play a significant role in the joint action and the progress of knowledge, just like all the qualitative elements related to students' engagement we have reported previously. These clues are confirmed by the Transana outputs (see Table 2): students drive or share the topogenesis with the teacher during 19 episodes (out of 49), i.e. 19 minutes out of 36 devoted to optics knowledge. 
Furthermore, the pace of the chronogenesis is generally maintained thanks to the maieutic process (as in Extract 4) and to the students' activity revivals operated by the teacher. But sometimes, Marie slows down the chronogenesis when she gives rise to a discussion (as in Extract 3) for the students to build or to appropriate a part of the knowledge at stake (9 episodes). Nevertheless, when the discussion becomes unproductive (as in Extract 5) or when the maieutic process fails, she regulates the learning game as described previously, and this helps to revive or speed up the chronogenesis for a while (11 episodes out of 49).

\section{Discussion}

The first step of this discussion concerns the teacher's practices and their interpretation. Next, we will compare their characteristics which lead to a productive disciplinary engagement with the four principles theorized by Engle. This comparison will lead us to connect elements of Engle's frame to elements of the JATD.

\subsection{Interpretation of the teacher's practices: a quest for a balance between questions and elements or processes provided to answer them}

We claim that the previous description can be summed up by: (1) no concession in the level of the knowledge taught as defined by the curriculum; (2) a permanent and successful quest for a balance between the nature of problems and questions put to the class on the one hand and, on the other hand, the help to answer them (maieutic process, regular identification of the knowledge at stake, delimitation of the elements submitted to discussion, delimitation of the relevant features of the milieu, frequent institutionalizations, formulation of the conclusion when the students do not succeed in doing it). Obtaining this balance in a class located in a disadvantaged urban area is very hard. It needs the lesson development to be closely monitored: the mesogenetic process and the topogenetic 
movements at work must imperatively guarantee the steady progress of the chronogenesis to avoid student's off-task and noisy behaviour. This may occur when there is a shared participation in the mesogenesis, that is to say referring to the JATD a real joint action between the teacher and students. These elements may be related to the PDE framework.

\subsection{Relations between the teacher's practices and Engle's and Conant's four principles leading to $P D E$}

We assume that the nature of the observed instruction can be partially associated with Engle and Conant's four principles: problematizing, authority, accountability and resources.

First, we observed that the teacher problematized the learning environment, encouraging the students to take on problems related to the topic under discussion. At the same time, a part of the mesogenesis was controlled by the teacher who progressively designed a pertinent didactic milieu as a resource to help students in developing disciplinary reasoning. Thus, although the didactic milieu was elaborated in common, it nevertheless remained under the teacher's monitoring and, moreover, if we consider it as a resource, this resource is different from the resources proposed by Engle and Conant's (2002) model. For them, resources are multiple, including documents with discrepancies, time, and students' experience of debates and document management. They are also available for a long period. In our analysis, relevant resources encompass elements that are more situated and available on a micro time scale. They include individual conceptual ideas, which are brought or pointed out by students or/and by the teacher. We consider that these resources are co-constructed during the interactions under the teacher's monitoring. For example, while students discuss a question, the teacher highlights some relevant features or proposes 
new objects when students' arguments do not progress; she values students' relevant purposes and she excludes irrelevant objects or ideas, allowing students to go forward in their reasoning; she concludes herself the interactions when they become unproductive. Thus, the concept of mesogenesis allows us to consider the question of resources differently in this regular context related to the FSNC (very different from that described by Engle and Conant, 2002, linked to a large time scale). However, this discussion (during a symposium dedicated the PDE framework, see footnote 8) leads Engle (2011) to consider now that resources also "can be as situated and momentary as when the teacher introduces a particular idea into discussion while discouraging others". In any case, we observe the same balance between problematizing and resources in this lesson as a condition for obtaining PDE, even if the word "resource" has not totally the same meaning in this ordinary context than it has in the context of a community of learners analysed by Engle and Conant (2002).

Secondly, the shared topogenesis or the student-driven topogenesis we observed can be related to authority and accountability. During the lesson, every student has intellectual agency and this is important for they contribute to the mesogenesis with their own thoughts. From time to time, some of them are recognized as authors of their ideas. At the same time, balancing these criteria of authority (Forman and al., this issue), every student is accountable to him/herself and to his/her class peers for the arguments he/she uses during discussions and to a small extent, to disciplinary norms. Thus, the other two principles are present in the development of the lesson (e.g. see Extract 3). To conclude, the "authority-accountability" axis also plays an important role, allowing the students to participate in the didactic joint action and to develop PDE in this lesson. 
Therefore, we can say that relationships exist between the dynamics and intervention modalities observed in those ordinary practices and Engle \& Connant's four principles. Nevertheless, we should mention that, due to the context (a disadvantaged area and a constraining curriculum): 1) the teacher plays an important role, dealing with the different resources provided by her and the students at a micro level to maintain a balance between the two poles, problematizing and resources; 2) the students' authority and accountability remain at intermediate levels (for example, regarding accountability, the teacher generally ensures the disciplinary normativity of students' assertions).

In any case, in this class where teaching is governed by a national compulsory curriculum mixing a subject matter focus with an inquiry process, the analysis shows a successful optimization of a set of temporal, curricular, social and cultural constraints that leads to a productive disciplinary engagement (though its disciplinary dimension does not fully cover scientific practices but includes, as discussed in section 5.1, its significant stages). Regarding Engle's principles, the cost to pay in this context to obtain PDE is 1) an adaptation of what is meant by "resources"; 2) an ambition reduced to the lowest levels of accountability and authority. Even though we claim that these adjustments linked to the nature of the FNSC as well as their ingenuous implementation by this teacher lead to PDE, some questions remain. What could happen with more intellectually challenging or less engaging topics of the FNSC? In this class, students began physics five months ago and it was their first lesson in optics; therefore, students dealt only with qualitative reasoning and they did not need to use previous learnt knowledge, particularly mathematics relations. Besides, regarding a ball as a light source appeared somewhat strange to the students. Thus 
they were easily engaged in debating this assertion that conflicted with their opinion. Perhaps these elements could also account for a part of the observed PDE.

\subsection{Links between JATD and PDE frameworks: an outline}

In this section, we do not aim to merge the JATD and PDE frameworks and build a hybrid theory. This would require an in-depth epistemological analysis while we only sketch it. This section only discuss the elements that bring these frameworks closer.

At first sight, their aim and perspective differ:

- The JATD attempts to describe the teaching and the learning of a specific knowledge as a teacher's and students' joint action. Thus the first aim of this framework is to provide an understanding of this whole process.

- Drawing on socio-constructivism, the purpose of the PDE framework is to design a learning environment which empowers students in enacting disciplinary knowledge. Thus this framework is marked by a form of normativity since the learning environment aims to obtain a particular student's behaviour.

However, we assume that this framework have common dimensions. Both deal with teaching, learning and knowledge considered as a whole. The JATD is based on this point of view (see section 2). As for the PDE framework, it focuses on students' behaviour related to "disciplinary" knowledge and includes implicitly the teacher who has to create and maintain the conditions leading to a PDE in the class. The idea of a mutual adjustment between the teacher and the students related to knowledge at stake is at the core of the two frameworks. Furthermore, we consider that both deal with design and analysis. The descriptors of the JATD are helpful to think out a learning environment by deciding of a 
kind of didactic contract, a particular didactic milieu, a specific type of teacher's regulation, a way to devolve the situation. And on the other side, the identification at particular moments of the different levels of problematizing, authority and accountability, as well as the identification of the available resources provides information about the didactic joint action. In our mind, this set of elements allows to consider that a connection is possible between both frameworks and entitle us to discuss the links between their concepts.

Drawing on our study and on Engle (2011), we have already pointed out the close relations between the PDE "resources" and the didactic milieu even if its co-constructed character remains a particularity of the milieu according to the JATD. In any case, both the didactic milieu and resources have the same function.

As for authority and accountability, we assume that their different levels (see section 2.2) can be considered as outcomes of particular didactic contracts. According to Brousseau and Warfield (1999) the didactic contract concerns "the set of (specific) behaviours of the teacher which are expected by the student and the set of behaviours of the student which are expected by the teacher". For example, a particular contract would be that students wait for the teacher recognize them as authors of their ideas about a topic while the teacher waits for the students be accountable to their peers of these ideas. As such, we consider authority and accountability as descriptors of the effects of the didactic contract displayed from the students' side. Moreover, these concepts can also be used to interpret a particular topogenesis (and thus, the associated mesogenesis and chronogenesis). 
This discussion leads us to consider that resources and levels of authority as well as accountability can be used to describe the evolution of a learning game as the last is defined by a particular didactic milieu and a particular didactic contract.

Lastly, we suggest that problematizing and devolution offer a dialectical point of view of the same process. Problematizing is a students' deliberate activity that comprises at the same time, cognitive, affective and effective aspects. This process relies on an environment provided and regulated over the activity by the teacher. Devolution is a teacher's deliberate activity which is influenced by the outcomes of the student's actions. Thus its achievement is always uncertain. Therefore, devolution and problematizing deal with the same process that is described according two different (and complementary) points of view of a same joint action.

Finally, according to our analysis, we claim that the PDE framework and the JATD might complement each other and might have some overlapping relations that should be more explored by further research.

\section{Conclusion}

Our study, which was conducted using analyses at a micro level with the help of the JATD, has contributed to the identification of configurations of didactic action that seem to facilitate PDE during an ordinary physics lesson developed according to the FNSC in a school located in a sensitive urban area. To obtain PDE, the teacher problematizes the knowledge at stake and associates problems and questions to a help to solve them, providing the students with resources available at a micro level. Resources arise due to various processes used by the teacher: regular identification of the knowledge at stake, delimitation of the elements submitted to discussion, delimitation of the relevant features 
of the milieu, frequent institutionalizations, and formulation of the conclusion when the students do not succeed in doing it. Resources are produced during the interactions thanks to a joint participation in the mesogenesis, students having a significant place in the topogenesis. They are in keeping with a chronogenesis usually progressing thanks to a maieutic process. The students' PDE results from a balance between these two poles, problematizing and resources at a micro level, and is also supported by a certain level of authority and accountability.

Therefore, although the four principles stated by Engle and Conant probably have a general validity, they seem to a different significance in the particular context of a regular lesson in a disadvantaged area. The main difference lies in the way Engle and Conant and we ourselves consider "resources" in the two different contexts.

Lastly, even though students are engaged during this period, some of them are more engaged than others, regularly speaking or putting their hands up to intervene. This observation allows us to assume that PDE (at a collective level) can be linked to the design of the situation and to the four principles, but we think that it is also determined by local factors, such as results of the students and teacher's joint action and external factors, like personal, social and environmental factors. Some theories account for these last aspects through theories of motivation to learn (Pintrich \& Schunk, 1996), or the theory of relation to knowledge (Venturini, 2007). To our mind, these theories also must surely be combined with Engle's propositions if we want to understand why productive disciplinary engagement really occurs in a lesson or not. 
07/04/2014 21:04

\section{Acknowledgments}

We would like to thank Randi Engle for her relevant feedback and judicious advices on earlier drafts of this paper, as well as Leema Berland and John Leach for their very fruitful comments on this paper.

\section{References}

Amade-Escot, C., \& Venturini, P. (2009). Le milieu didactique : d'une étude empirique en contexte difficile à une réflexion sur le concept. Education et Didactique 3 (1), 7-43

Andersson, B., \& Karrqvist, C. (1983). How Swedish pupils aged 12-15 years, understand light and its properties. European Journal of Science Education, 5(4), 387-402.

Bautier, E., \& Goigoux, R. (2004). Difficultés d'apprentissage, processus de secondarisation et pratiques enseignantes : une hypothèse relationnelle. Revue Française de Pédagogie, 148, 89-100.

Bourdieu, P. (1992). Language and Symbolic Power. Cambridge: Polity Press

Brousseau, G., \& Warfield, V. M. (1999). The case Gaël. The study of a child with mathematical difficulties. The Journal of Mathematical Behavior, 18(1). Retrived February $1^{\text {st }} 2011$ from

http://www.math.washington.edu/ warfield/articles/gael/Gael20.html

Brousseau, G. (1997). Theory of Didactical Situations in Mathematics (N. Ballachef, M. Cooper, R. Sutherland, V. Warfield, Eds., Collected Papers). Dordrecht: Kluwer. 
Cobb, P., Gresalfi, M., \& Hodge, L. L. (2009). An interpretive scheme for analyzing the identities that students develop in mathematics classrooms. Journal for Research in Mathematics Education, 40(1), 40-68.

Collins, A., \& Ferguson, W. (1993). Epistemic forms and epistemic games: Structures and strategies to guide inquiry. Educational Psychologist, 28(1), 25-42

Derry, S. (2007 (Ed). Guidelines for Video Research in Education. Recommendations from an expert panel. Retrieved September $1^{\text {st }} 2010$ from http://drdc.uchicago.edu/what/video-research-guidelines.pdf.

Engle, R. A., \& Conant, F. R. (2002). Guiding principles for fostering productive disciplinary engagement: explaining an emergent argument in a community of learners' classroom. Cognition and Instruction, 20(4), 399-483.

Engle, R. A. (2011). The productive disciplinary engagement framework: Origins, key concepts and developments. In D.Y. Dai (Ed.), Design research on learning and thinking in educational settings: Enhancing intellectual growth and functioning (pp.161-200). London: Taylor \& Francis.

Ford, M. J., \& Forman, E. A. (2006). Redefining disciplinary learning in classroom contexts. Review of Research in Education, 30, 1-32.

Lidar M, Lundqvist E, Ostman L (2006). Teaching and learning in the science classroom: The interplay between teachers' epistemological moves and students' practical epistemology. Science Education, 90, 148-163. 
Ligozat, F. \& Schubauer-Leoni, M.-L. (2009, July). The joint action theory in didactics: Why do we need it in the case of teaching and learning mathematics? In Proceedings of the Sixth Conference of European Research in Mathematics Education (pp. 8392). Retrieved September $1^{\text {st }} 2010$ from http://educmath.inrp.fr/Educmath/ recherches/actes-en-ligne/1wg9.pdf.

Leutenegger, F. (2003). Etude des interactions didactiques en classe de mathématiques : un prototype méthodologique. Bulletin de psychologie, 56(4), 559-571.

Ministère de 1'Education Nationale (MEN). (2007). Programmes des enseignements de mathématiques, de sciences de la vie et de la Terre, de physique et chimie pour le collège. $B O E N, 6,109-144$.

Mercer, N. (2000). Words \& Minds. How to use language to think together. Routledge: London

Morrison, D. \& Collins, A. (1996). Epistemic fluency and construction of learning environments. In B. G. Wilson (Ed), Constructivist Learning Environments. Case studies in Instructional Design (pp. 107-119). Educational Technology Publication: Englewood Cliffs (NJ)

Mortimer, E., Massicame, T., Tiberghien, A., \& Buty C. (2005). Una metodologia de análise e comparação entre a dinâmica discursiva de salas de aulas de ciências utilizando software e sistema de categorização de dados em vídeos: Parte 1, dados quantitativos. V Encontro Nacional de Pesquisa emEnsino de Ciências. Bauru: ABRAPEC. 
Osborne, J., Driver, R., \& Simon, S. (1998). Attitudes to science: issues and concerns. School Science Review, 79 (288), 27-33.

Pintrich, P. R. \& Schunk, D. H. (1996). Motivation in education: theory, research and applications. Englewood Cliffs : Prentice Hall.

Rochex J.-Y. (1997). Les ZEP un bilan décevant. In J.-P. Terrail (Ed.), La scolarisation de la France : Critique de l'état des lieux, (pp. 123-140). Paris : La dispute.

Rochex, J.-Y., \& Kheroubi, M. (2004). La recherche en éducation et les ZEP en France. Apprentissage et exercice professionnel en ZEP : résultats, analyse, interprétations. Revue Française de Pédagogie, 146, 115-190.

Scott, P., Mortimer, E., \& Aguiar, O. (2006). The tension between authoritative/dialogic discourses: a fundamental characteristic of meaning making interactions in highschool science lessons. Science Education, 90(4), 605-631.

Sensevy, G. (2007). Des catégories pour décrire et comprendre l'action didactique. In G. Sensevy \& A. Mercier (Dir.), Agir ensemble : l'action didactique conjointe du professeur et des élèves (pp. 13-49). Rennes : Presses Universitaires de Rennes.

Sensevy, G. (2009 - January). Outline of a joint action theory in didactics. In Proceedings of the Sixth Conference of European Research in Mathematics Education (pp. 113122). Lyon, France. Retrieved September $1^{\text {st }} 2010$ from http://educmath.inrp.fr/ Educmath/recherches/actes-en-ligne/1wg9.pdf 
Sensevy, G. (2011). Overcoming fragmentation: Towards a joint action theory in didactics. In B. Hudson \& M. A. Meyer (Eds.), Beyond fragmentation: Didactics, learning and teaching in Europe (pp. 60-76). Opladen: Barbara Budrich.

Sensevy, G. (2012). About the Joint Action Theory in Didactics. Zeitschrift für Erziehungswissenschaft, 2(11). DOI 10.1007/s11618-012-0305-9

Sensevy, G., Schubauer-Leoni, M.-L., Mercier, A., Ligozat, F., \& Perrot, G. (2005). An attempt to model the teacher's action in the mathematic class. Educational Studies in Mathematics, 59, 153-181.

Selley, N.J. (1996). Towards a phenomenography of light and vision, International Journal of Science Education, 18(7), 837-846.

Sherry, L., \& Trigg, M. (1996). Epistemic forms and epistemic games. Educational Technology, 36(3), 38-44

Tiberghien, A., Malkoun L., Buty, C., Souassy, N., \& Mortimer E. (2007). Analyse des savoirs en jeu en classe de physique à différentes échelles de temps. In G. Sensevy \& A. Mercier (dir.), Agir ensemble : l'action didactique conjointe du professeur et des élèves (pp. 93-121). Rennes : Presses Universitaires de Rennes.

Venturini, P. (2007). The Contribution of the Theory of Relation to Knowledge to Understanding Students' Engagement in Learning Physics. International Journal of Science Education, 29(9), 1065-1088.

Venturini, P. \& Amade-Escot, C. (2009a - August). Conditions fostering productive disciplinary engagement during a regular physics lesson in a depressed area school. 
In C. Buty (chair) \& R. A. Engle (organizer), Developing and challenging the productive disciplinary engagement framework. Symposium presented at the EARLI conference, Amsterdam.

Venturini, P., \& Amade-Escot, C. (2009b). Enseigner la physique en milieu difficile : coconstruction de la référence en classe dédoublée et en classe entière. Revue Suisse des Sciences de l'Education, 31(2), 419-439.

Venturini, P., \& Tiberghien, A. (2012). Potential Learning Outcomes Inferred from French Curricula in Science Education. In S. Bernholt, K. Neumann, \& P. Nentwig (Eds.), Making It Tangible - Learning Outcomes in Science Education (pp. 475-509). Münster: Waxmann.

Wittgenstein L. (1997). Philosophical Investigations. Oxford: Blackwell. 


\begin{tabular}{|c|c|c|}
\hline $\begin{array}{l}\text { Time } \\
\text { (minutes) }\end{array}$ & Nature and organization of the activities & Knowledge at stake \\
\hline $1-2$ & Students settle down & \\
\hline $3-5$ & $\begin{array}{l}\text { What is optics? } \\
\text { Collective discussion }\end{array}$ & $\begin{array}{l}\text { Identification of phenomena } \\
\text { students may consider as } \\
\text { belonging to optics }\end{array}$ \\
\hline $6-12$ & $\begin{array}{l}\text { Classify } 4 \text { light sources (lamp, sun, snow, } \\
\text { ping-pong ball) according to their } \\
\text { characteristics }^{l} \\
\text { Collective discussion }\end{array}$ & $\begin{array}{l}\text { The primary sources emit } \\
\text { light, other sources are } \\
\text { secondary sources }\end{array}$ \\
\hline $13-20$ & $\begin{array}{l}\text { Do we see a white ball in darkness? } \\
\text { Predictions about the vision in darkness of 1) } \\
\text { a lamp, 2) a white ball, 3) a white ball lit by a } \\
\text { white light, and then by a red light. } \\
\text { Teacher's experiment to test the students' } \\
\text { predictions. } \\
\text { Individual formalization of the observations } \\
\text { in the student document. } \\
\text { Oral checking of the responses. } \\
\text { Institutionalization of the observations } \\
\text { Dictated institutionalization }\end{array}$ & $\begin{array}{l}\text { A secondary source is } \\
\text { visible only if it is } \\
\text { illuminated by a primary } \\
\text { source }\end{array}$ \\
\hline $21-34$ & Why do we see a ping-pong ball even though & A secondary source diffuses \\
\hline
\end{tabular}




\begin{tabular}{|l|l|l|}
\hline \multirow{2}{*}{$\begin{array}{l}\text { Collective debate to interpret the observations } \\
\text { made during the previous experiment } \\
\text { Written formalization of the conclusions } \\
\text { under students' proposals }\end{array}$} & the light it receives \\
\hline $35-48$ & $\begin{array}{l}\text { Classification of different light sources } \\
\text { Individual exercises }\end{array}$ & Reinvestment of the \\
& $\begin{array}{l}\text { Oral correction } \\
\text { Dictated institutionalization }\end{array}$ & properties of primary and \\
& $\begin{array}{l}\text { Who can see the boat on the sea? (Use of a } \\
\text { strip cartoon) } \\
\text { Individual exercise (which forms a bridge to } \\
\text { the next lesson). }\end{array}$ & Introduction to the \\
\hline 55 & $\begin{array}{l}\text { Bell } \\
\text { object (opening the eyes and }\end{array}$ \\
\hline
\end{tabular}

Table 1: Synopsis of the lesson (The questions appearing in the students' document are in italics in this table) 


\begin{tabular}{|c|c|c|}
\hline & $\begin{array}{l}\text { Number of } \\
\text { episodes }\end{array}$ & Duration * \\
\hline Entire lesson & 70 & 55 minutes \\
\hline Episodes dedicated to optics in the lesson & 49 & 36 minutes \\
\hline students' collective work & 33 & 26 minutes \\
\hline $\begin{array}{l}\text { Students' discourse coordinated with others during collective } \\
\text { work }\end{array}$ & 18 & $\mathbf{1 3}$ minutes \\
\hline $\begin{array}{l}\text { Students' questions or inputs connected with the optics topic } \\
\text { under discussion during collective work }\end{array}$ & 9 & 8 minutes \\
\hline Collective maieutic platonic process & 17 & 15 minutes \\
\hline $\begin{array}{l}\text { Specific regulations helping the students to improve their } \\
\text { strategies in the learning games }\end{array}$ & 19 & 17 minutes \\
\hline Institutionalization of elements of knowledge as it progresses & 13 & 9 minutes \\
\hline Students drive or share the topogenesis with the teacher & 19 & 17 minutes \\
\hline Slowing down of the chronogenesis to give rise to a discussion & 9 & 6 minutes \\
\hline $\begin{array}{l}\text { Reviving or speeding up of the chronogenesis with the specific } \\
\text { regulations }\end{array}$ & 11 & 8 minutes \\
\hline
\end{tabular}

Table 2: Transana outputs (in bold the indicators mentioned in this paper). *The duration is rounded off to the next minute if the number of seconds is higher than 30 , and to the previous minute when it is lower than 30 
1 The main characteristics of the new FSNC are presented in Venturini and Tiberghien (2012). In the investigation process that it includes, we find elements we can relate to the four principles leading to PDE: problematizing, resources, authority and accountability.

${ }^{2}$ An "ordinary" lesson is a lesson designed by the teacher without any propositions from the researcher

3 The term "Didactic" has not the pejorative meaning it can have in English. It means "related to the transmission of knowledge" as it is understood in the European research.

4 An epistemic game is associated to one (or more) epistemic form(s). "Epistemic forms are 'target structures' that guide the inquiry process [that leads to the construction of knowledge] (Morrison \& Collins, 1996, p. 109). It shows how knowledge is organized. Examples of epistemic forms include among others, list, table, molecular structure model, periodic table of elements, binary tree, cognitive map, cause-effect diagram, stage model etc. The completion or creation of the structure that satisfies the inquiry is the object of the epistemic game. "Epistemic games are sets of moves, entry conditions, constraints, and strategies that guide the construction of knowledge around a particular epistemic form” (id.). Examples of epistemic games include among many others creating a theory by presenting evidence for and against, writing an outline, developing a concept map, building a regression analysis model, determining functions necessary to update a database etc. (Sherry \& Trigg, 1996, p. 41). Thus we might say that epistemic games as intended by Morrison $\&$ Collins are at stake in learning games.

5 Mercer's book aims to describe "how we use language to think together". He introduces the term of "interthinking" "in order to focus attention on the joint, co-ordinated intellectual activity which people regularly accomplish using language" (Mercer, 2000, p.16). For him, context is "a mental phenomenon, it consists of whatever information listeners (or readers) use to make sense of what is said (or written)" (p. 20). Context is not "something that exists independently of people. In order to combine their intellectual efforts people have to strive to create foundations of common contextualized knowledge. People do this by drawing on whatever information resources they think are relevant. These contextual resources are likely to be found 
in such things as: the physical surroundings; the past shared experience and relationship of the speakers; the speakers' shared tasks and goals; the speaker's experience of similar kind of conversations" (p. 44).

${ }^{6}$ Normative identity "comprises both the general and the specifically mathematical obligations that delineate the role of an effective student in a particular classroom. A student would have to identify with these obligations in order to develop an affiliation with classroom mathematical activity and thus with the role of an effective doer of mathematics, as they are constituted in the classroom". These general and mathematical obligations the students have to identify are related to the idea of norm. "A norm can be defined as recurrent pattern in joint activity that is regulated by the expectations that the teacher and students have for each other's actions in particular situations" (Cobb, Gresalfi and Hodge (2009, p. 44). Moreover, Cobb and al. note "that students' general and specifically obligations are constituted in the course of ongoing classroom interactions" (idem p. 46).

7 The Latin expression "proprio motu" means "by one's own volition; on one's own initiative".

${ }^{8}$ Engle (In Press) has added these "situated and momentary" resources to the list of resources proposed by Engle \& Connant (2002). The contribution of these situated and momentary resources available at a micro time scale to the PDE framework has been introduced by Venturini and Amade-Escot (2009a) during a symposium dedicated to PDE.

${ }^{9}$ See http://www.transana.org/

${ }^{10}$ The remaining time was devoted to: students settling down at the beginning of the lesson ( 2 minutes), the setting of the students' tasks (9 minutes), a discussion about peripheral physics topics (4 minutes) and, admonitions of students ( 3 minutes).

${ }^{11}$ The time allocated to the distinction between primary and secondary sources in the FSNC syllabus does not allow the students to be fully "constructors" of claims.

${ }^{12}$ Considering the size of this article, we have limited the data exemplifying our analysis to one extract that is emblematic of our findings. 
${ }^{13}$ A pedagogical set of verbal interactions aiding to the definition and interpretation of thoughts. Plato gives the first known reference to the maieutic principle, as a method used by Socrates. According to Plato, several traits in Socrates' activity make it resemble a midwife's art though Socrates operates with ideas.

${ }^{14}$ These teacher's actions may echo the notion of "re-constructive move" proposed by Lidar, Lundqvist and Östman (2006). It is one of the five "epistemological moves" the teacher does when he/she teaches in order that students learn. The particular "re-constructive" move occurs when the teacher makes the students pay attention to that the facts they have already noticed, "are important to recognize and to write down", or to pursue with. However, considering this type of action as a mesogenetic one within the JATD framework focuses more on the effect of the action on the learning environment than on the action itself.

15 This action echoes to another epistemological move (see note 14) called "instructional move" where the teacher points out what the students need to do to find the solution. Here she indicates what the students have to know to find the solution.

${ }^{16}$ Referring to Bruner (1956), scaffolding represents the helpful interactions between adult and child that enable the child to do something beyond his or her independent efforts. 